\title{
Target Regulation of a Motor Neuron-Specific Epitope
}

\author{
Edmond W. Chen, Sofia Loera, and Arlene Y. Chiu \\ Division of Neurosciences, Beckman Research Institute, City of Hope, Duarte, California 91010
}

In the adult rat nervous system, motor neurons are recognized specifically by a monoclonal antibody, MO-1. Because binding by MO-1 is lost following axotomy, contact with the target may regulate this motor neuron-specific epitope. To test this hypothesis, we examined the recovery of MO-1 immunoreactivity in hypoglossal neurons following unilateral damage to the hypoglossal nerve. During the first week following nerve crush, neurons in the ipsilateral hypoglossal nucleus lost all immunoreactivity for MO-1. Antibody binding returned with time, and by 4 weeks, $80 \%$ of the injured neurons had recovered the MO-1 epitope. Since motor neurons reinnervate their original targets readily following nerve crush, it appears that MO-1 binding is recovered when motor neurons return to their original target muscles in the tongue. When the hypoglossal nerve was cut and inserted into a foreign muscle nearby (the sternomastoid muscle), the MO-1 epitope was not detected in the injured neurons, even when examined 6 weeks after surgery. However, if the sternomastoid muscle was denervated prior to insertion of the hypoglossal nerve, thus allowing the hypoglossal nerve to synapse with this foreign target, increasing numbers of hypoglossal neurons reacquired MO-1 immunoreactivity with time. Our results suggest that the MO-1 epitope is only expressed in motor neurons that are in synaptic contact with skeletal muscle. Thus, a property that distinguishes mature motor neurons from other neuronal phenotypes appears to be regulated by direct synaptic interaction with the postsynaptic target.

[Key words: motor neurons, brainstem, peripheral nerve injury, reinnervation, synapse formation, neuromuscular junction, retrograde signals, skeletal muscles, immunohistochemistry]

Bidirectional communication across the synapse maintains the dynamic relationship between neurons and their targets (Jessell and Kandel, 1993). At the neuromuscular junction, transynaptic interactions can influence both the development and the maintenance of the phenotype of motor neurons as well as the muscle fibers they innervate (Hall and Sanes, 1993; Connor and Smith,

\footnotetext{
Received July 18, 1994; revised Aug. 29, 1994; accepted Sept. 7, 1994.

We thank Lupe Magallenes for excellent technical assistance, Mariko Lee for advice with photography, Kay Seymour-Laurent for the production of Figure 4, and Richard Hammerschlag, Jeff Markham, Karina Meiri and Rick Wetts for critical reading of the manuscript. Monoclonal antibodies to choline acetyltransferase were generously provided by Paul Salvaterra. This project was supported by Grant RO1HD26810 from the National Institute of Child Health and Human Development to A.Y.C.

Correspondence should be addressed to Arlene Y. Chiu, Division of Neuroscience, Beckman Research Institute of the City of Hope, 1450 East Duarte Road, Duarte, CA 91010.

Copyright (C) 1995 Society for Neuroscience $0270-6474 / 95 / 151556-11 \$ 05.00 / 0$
}

1994; Haydon and Zoran, 1994). Anterograde communication in the form of synaptic transmission has both transient and longterm effects on muscle fibers. In addition to the activation of muscle contraction, electrical signaling regulates the expression of components of the postsynaptic membrane such as acetylcholine receptors (Berg and Hall, 1975; Fanbrough, 1979; Fontaine et al., 1987; Goldman et al., 1988; Gu and Hall, 1988; Klarsfeld et al., 1989), and cell adhesion components such as NCAM (Chiu et al., 1986; Sanes et al., 1986). The rate of electrical activity can alter the phenotype of the muscle fiber (Salmons and Sreter, 1976; Rubenstein et al., 1978; Eftimie et al., 1991; Gunning and Hardeman, 1991). Release of other molecules by the presynaptic cell may not affect synaptic transmission directly, but can act locally on the target to alter the distribution of the synaptic apparatus. For example, motor neurons express the extracellular matrix component, agrin, which induces clustering of acetylcholine receptors at the neuromuscular synapse (reviewed by McMahan et al., 1992). Other molecules modify gene expression in the postsynaptic cell: acetylcholine receptor inducing agent (ARIA), calcitonin gene-related peptide, and molecules in synaptic basal lamina can regulate transcription in subsynaptic nuclei of muscle fibers (New and Mudge, 1986; Falls et al., 1990; Goldman et al., 1991; Brenner et al., 1992; Jo and Burden, 1992). Together, these observations demonstrate that the presynaptic neuron can, via a panoply of mechanisms and molecules, direct the structure, function, and phenotype of the postsynaptic cell.

The postsynaptic partner, in turn, exerts profound effects on the presynaptic neuron (Voyvodic, 1989; Erzurumlu et al., 1993; Conner and Smith, 1994; Haydon and Zoran, 1994; Murphey and Davis, 1994; Schotzinger et al., 1994). For example, diffusible molecules such as nitric oxide and carbon monoxide have been implicated as retrograde signals for the induction of longterm potentiation in the hippocampus (Hawkins et al., 1994; Schuman and Madison, 1994). In addition, target-derived neurotrophic factors are known to promote the survival and differentiation of presynaptic neurons (Korsching, 1993; Nishi, 1994). Even the transmitter phenotype of a neuron can be altered by signals derived from the target (Patterson and Nawa, 1993; Schotzinger et al., 1994). Thus, the survival, nature, and function of a neuron may be critically dependent on retrograde cues from its postsynaptic associates.

In the rodent spinal cord, somatic motor neurons originate from multipotent neuroepithelial cells that also give rise to preganglionic motor neurons of the intermediolateral column (Phelps et al., 1988, 1991; Leber et al., 1990). These two lineally related populations of cholinergic neurons both extend axons out to targets in the periphery: somatic motor neurons synapse upon skeletal muscles, while preganglionic neurons innervate postganglionic neurons of the autonomic nervous system. One of the 
few characteristics by which these neuronal phenotypes can be distinguished is an epitope that is recognized by a monoclonal antibody, MO-1. Several lines of evidence suggest that MO-1 immunoreactivity is regulated in some way by the postsynaptic target. First, MO-1 binding is observed only in motor neurons innervating striated muscle (Urakami and Chiu, 1990). Secondly, immunoreactivity is not detectable until the second week after birth (Chiu et al., 1993), at a time when neuromuscular units undergo their final stages of differentiation and synaptic consolidation (Jansen and Fladby, 1990). Finally, MO-1 immunoreactivity is lost following axotomy, but returns with regeneration (Chiu et al., 1993). The question, thus, arises as to whether this distinguishing feature of motor ncurons is related to the establishment of the adult pattern of connectivity and a neuron's final choice of target.

To address this issue, we have examined the recovery of the MO- 1 epitope under different conditions of regeneration and reinnervation. Our results indicate that maintenance of $\mathrm{MO}-1$ immunoreactivity requires synaptic contact with muscles, thereby suggesting that retrograde, transsynaptic signals from muscle to nerve regulate the biochemical phenotype of motor neurons. A preliminary account of this work has been published in abstract form (Chen et al., 1993).

\section{Materials and Methods}

Antibodies and reagents. Hybridoma supernatant of monoclonal antibody MO-1 was generated as previuusly described (Urakami and Chiu, 1990). Monoclonal antibody, 1E6, which is specific for choline acetyltransferase (ChAT), was generously provided by Dr. P. Salvaterra (Duarte, CA). A monoclonal antibody to synaptophysin was purchased from Boehringer-Mannheim Biochemicals (Indianapolis, IN) and polyclonal, secondary antibodies labeled with fluorescein were obtained from Chemicon Chemicals Inc. (Temecula, CA). Wheat germ agglutinin (WGA), goat anti-WGA, and the Vectastain $A B C$ kit for visualizing goat antibodies were all obtained from Vector Laboratories (Burlingame, CA). Rhodamine-labeled $\alpha$-bungarotoxin was purchased from Molecular Probes (Eugene, OR). All other reagents were obtained from Sigma (St. Louis, MO).

Animals. Adult female Sprague-Dawley rats weighing between 100 $200 \mathrm{gm}$ were anesthetized with an intraperitoneal injection of Nembutal $(1 \mathrm{ml} / \mathrm{kg}$ body weight) prior to surgery. To produce a peripheral nerve crush, the left hypoglossal nerve was exposed under the digastric muscle, and pressure was applied for 15-30 sec with fine watchmaker's forceps across the width of the nerve (Fig. $1 B$ ). In experiments where axotomy was required, the nerve was first ligated with surgical sutures at two sites approximately $1 \mathrm{~cm}$ apart. The nerve segment between the sutures was then excised to prevent fusion of the two cut and ligated ends (Fig. $1 C$ ). In experiments where the injured nerve was brought in close contact with a foreign muscle, the left hypoglossal nerve was transected but not ligated. Instead, the proximal end was inserted directly into the belly of the ipsilateral sternomastoid muscle and tethered in place with surgical silk (Fig. $1 D, E$ ). To produce a denervated muscle target, the sternomastoid nerve, which normally innervates the sternomastoid muscle, was also cut and removed at this time (Fig. 1E).

Twenty-four hours prior to the end of the experiment, a cumulativc volume of $30 \mu \mathrm{l}$ of WGA $(1 \mathrm{mg} / \mathrm{ml}$ in water) was injected via multiple spot injections to either the tongue or the sternomastoid muscle under anesthesia. For MO-1 immunoreactivity, animals were sacrificed with an overdose of carbon dioxide a day after receiving WGA injections, and the brainstem removed for immunohistochemical analysis. Freshfrozen sections, $12 \mu \mathrm{m}$ thick, were collected on slides, fixed with acetone, and stored at $-20^{\circ} \mathrm{C}$ until used. The sternomastoid muscles were also removed, flash frozen, and sectioned as previously described (Sanes and Chiu, 1983) for examination of synapses. To examine the return of ChAT, animals were anesthetized, then fixed by intracardial perfusion with freshly prepared, $4 \%$ paraformaldehyde in phosphate buffer, $\mathrm{pH}$ 7.4. The brainstem was dissected and immersed in fixative for $24 \mathrm{hr}$. After rinsing off excess fixative, the tissue was cryoprotected in $30 \%$ sucrose in phosphate buffer and sectioned on a cryostat. Serial scctions, $40 \mu \mathrm{m}$ thick, were stored in phosphate-buffered saline at $4^{\circ} \mathrm{C}$ until used.
A. Normal

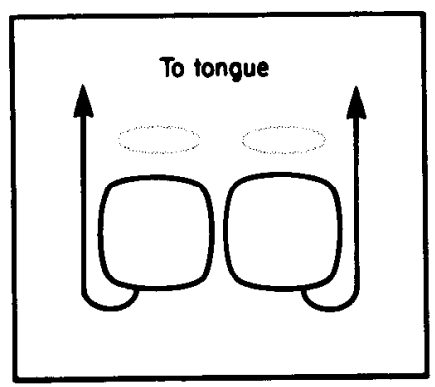

B. Nerve crush

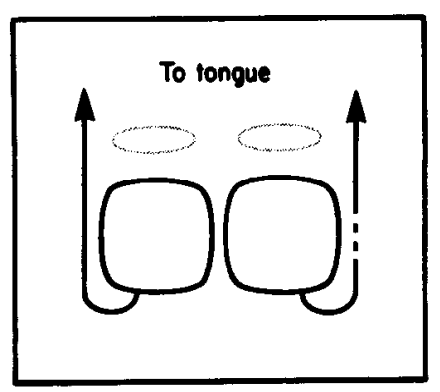

D. Nerve inserted into innervated foreign muscle

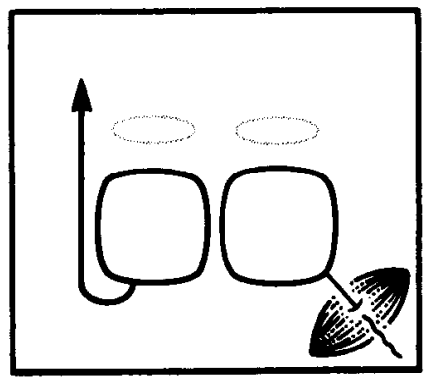

C. Nerve transection

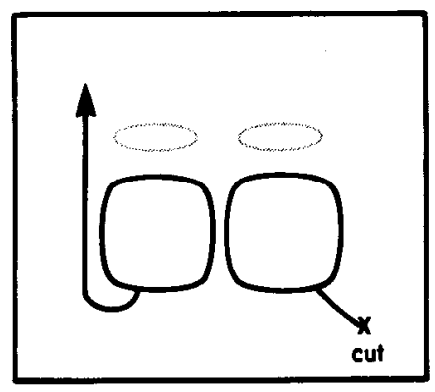

E. Nerve inserted into denervated foreign muscle

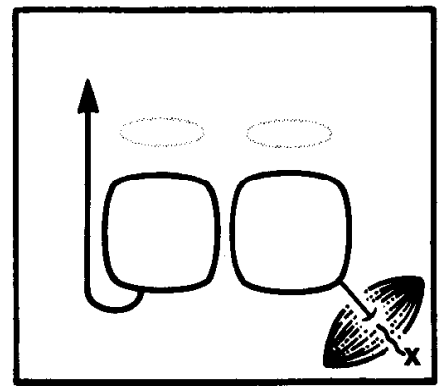

Figure 1. Experimental paradigms to study the requirement for synaptic contact with muscle. The solid lines outline the hypoglossal nuclei; the dotted lines represent the dorsal motor nuclei of the vagus nerve. $A$, Normally, hypoglossal neurons extend axons into the ipsilateral hypoglossal nerve to innervate the tongue. $B$, The left hypoglossal nerve was crushed and permitted to regenerate and reinnervate the muscles of the tongue. $C$, The left hypoglossal nerve was transected and the cut ends were ligated to prevent regeneration. $D$, The transected hypoglossal nerve was inserted into the belly of the left sternomastoid muscle with its original innervation intact, thus preventing synapse formation by the implanted hypoglossal axons. $E$, The cut hypoglossal nerve was inserted into a denervated sternomastoid muscle, which now allowed synapse formation by the hypoglossal axons.

Immunohistochemistry. Consecutive, fresh-frozen sections spanning the hypoglossal nucleus were collected for localization of MO-1 binding, for Nissl staining, and for examination of retrograde transport of WGA. Alternate sections were treated for MO-1 immunoreactivity as previously described (Chiu et al., 1993). To detect WGA, thawed sections of brainstem were tixed briefly in freshly prepared, $4 \%$ parafor-

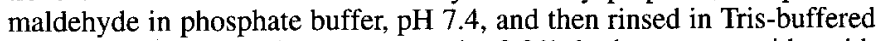
saline (TBS). Following treatment in $0.3 \%$ hydrogen peroxide with $0.1 \%$ sodium azide in TBS to inactivate endogenous peroxidase activity, the sections were preincubated for $1 \mathrm{hr}$ at room temperature with TBS containing $1.5 \%$ normal horse serum, to reduce nonspecific binding. Sections were incubated overnight at $4^{\circ} \mathrm{C}$ in polyclonal antibodies to WGA (goat anti-WGA, Vector Laboratories), diluted to a final concentration of $1: 500$ in TBS containing $0.1 \%$ bovine serum albumin (BSA). All subsequent rinsing was carried out in TBS containing 2.5\% BSA. 
Normal

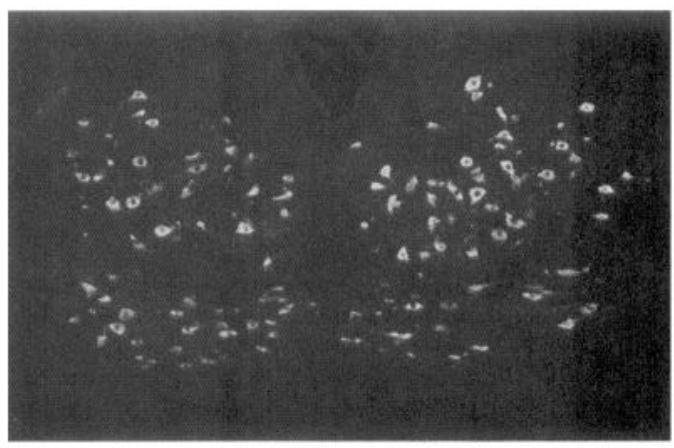

MO-1
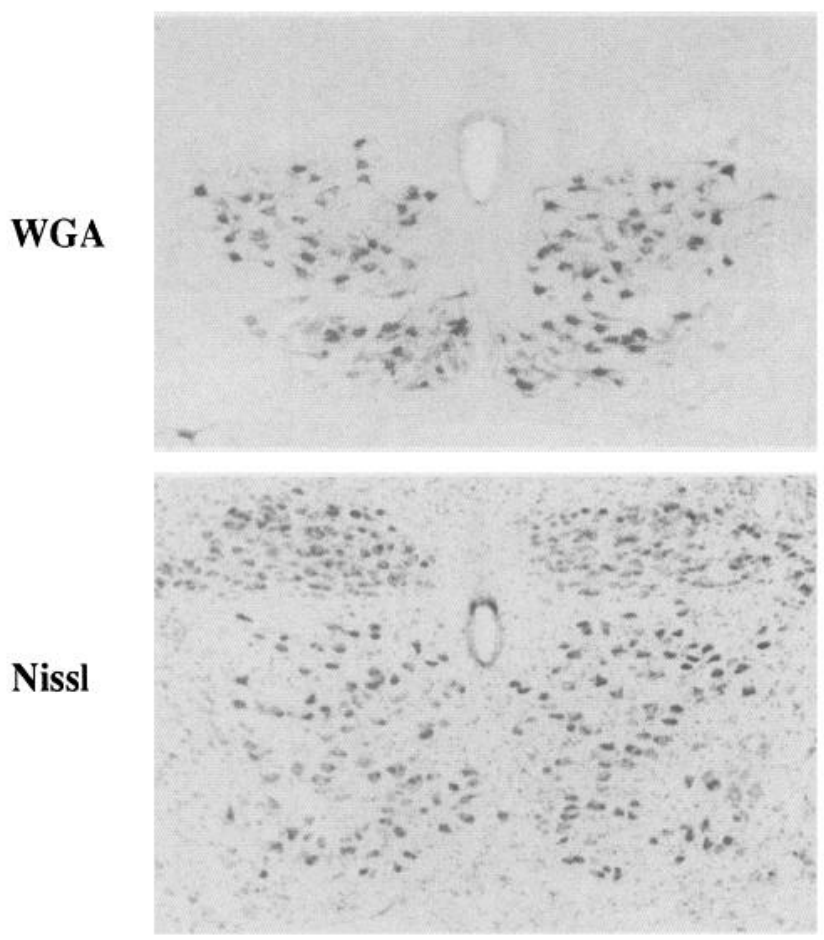

Unilateral axotomy
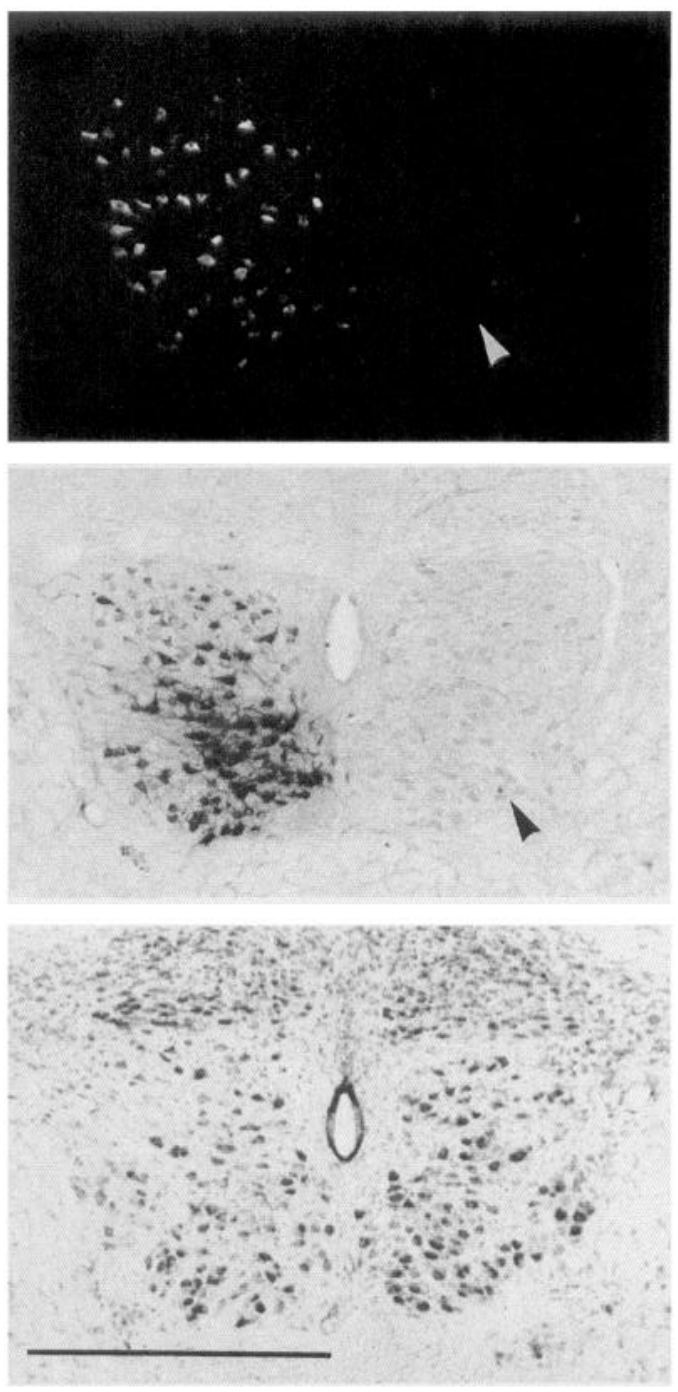

Figure 2. MO-1 immunoreactivity is lost following damage to the peripheral nerve. Brainstem sections from a control rat and a rat $7 \mathrm{~d}$ after unilateral transection of the hypoglossal nerve were reacted for MO-1 binding, for wheat germ agglutinin (WGA) immunoreactivity, and Nissl stained for total cell number. The tracer, WGA, was injected into the tongue to identify cells in contact with tongue muscles. Under normal circumstances, WGA fills neurons in both sides of the hypoglossal nucleus, and both populations were immunoreactive for MO-1. While cell counts of Nissl-stained sections show that there was no cell loss with axotomy, the axotomized population was devoid of WGA, and was not stained by MO-1. Arrowheads point to the axotomized population. Preganglionic neurons of the dorsal motor nuclei of the vagus nerve, seen with Nissl stain immediately above the hypoglossal nuclei, were devoid of MO-1 binding in all animals. Scale bar, $500 \mu \mathrm{m}$.

Sites of antibody binding were localized with biotinylated secondary antibodies and horseradish peroxidase (HRP)-coupled avidin, according to manufacturer's directions (ABC kit, Vector Laboratories). HRP reaction product was visualized with diaminobenzidine, intensified with cobalt and nickel.

Immunoreactivity for ChAT was carried out on floating, $40 \mu \mathrm{m}$ thick fixed sections of the brainstem as previously described (Chiu et al., 1993), using a monoclonal antibody specific for the enzyme.

To visualize pre- and postsynaptic elements at the neuromuscular junction, sections of the sternomastoid muscle were double labeled with a monoclonal antibody to synaptophysin (Boehringer-Mannheim), followed by fluoresceinated secondary antibodies, and with rhodaminelabeled alpha-bungarotoxin. A 1:30 dilution of the antibody to synaptophysin in phosphate-buffered saline (PBS) was applied onto $10 \mu \mathrm{m}$ thick unfixed sections of muscle overnight at $4^{\circ} \mathrm{C}$. After extensive rinses in PBS, the sections were incubated with fluoresceinated goat-antimouse Ig (diluted 1:100 in PBS and preadsorbed in rat liver acetone powder to eliminate background staining). The solution of secondary antibodies also contained rhodaminated alpha-bungarotoxin (1:3000 dilution) to identify postsynaptic sites. After rinses in PBS to remove excess labels, the sections were mounted in $0.2 \% p$-phenylenediamine to reduce quenching during viewing and photography.

\section{Results}

Motor neurons of the hypoglossal nucleus innervate the striated muscles of the tongue, with each half of the nucleus sending all of its axons via the ipsilateral hypoglossal nerve (Fig. $1 A$ ). Thus, unilateral injury to the hypoglossal nerve affects only motor neurons on the ipsilateral side of the nucleus, leaving the contralateral side as an undamaged control (Fig. $1 B, C$ ). Although immature motor neurons perish following axotomy, motor neurons in adult animals are more resistant to injury (Kuno, 1990); the survival and presence of axotomized motor neurons in our experiments were documented with Nissl-stained sections. Seven days following transection of the left hypoglossal nerve, the control and experimental sides of the nucleus bear similar num- 
bers of neurons (Fig. 2). Unilateral transection of the hypoglossal nerve was assayed by injecting wheat germ agglutinin (WGA) into the tongue. Motor neurons within the uninjured half of the nucleus were retrogradely labeled by the tracer; however, the damaged motor neurons were not (Fig. 2). Under these conditions of injury, which did not allow reinnervation, immunoreactivity for MO-1 was permanently lost from the axotomized motor neurons (Fig. 2).

To determine if contact with muscle was necessary for recovery of the epitope, the left hypoglossal nerve was crushed, and the animals sacrificed at different times following injury (Fig. $1 B$ ). In contrast to acute axotomy, motor nerves regenerate following nerve crush and return to their original target muscles. In this case, too, the damaged neurons lost MO-1 binding within a week following nerve crush; however, immunoreactivity for MO-1 returned with a time course that paralleled regeneration and reinnervation of the tongue (Fig. 3, left column; Table 1). It has been demonstrated that electrical stimulation of the hypoglossal nerve once again could elicit twitching of the tongue 4 weeks after nerve crush (Wood et al., 1990). We find that within 4 weeks of the operation, staining for the MO-1 epitope on the two sides of the hypoglossal nucleus was virtually indistinguishable. Therefore, hypoglossal motor neurons recovered the MO-1 epitope upon reinnervation of their original muscles in the tongue.

In this first set of experiments, the motor axons returned to their original targets, which were denervated by the nerve crush. We cannot tell from these results if simple contact with muscle will suffice to induce the return of MO-1 immunoreactivity, or whether actual synapse formation is required. To distinguish between these two possibilities, experiments were designed that placed motor neurons in physical, but not synaptic, contact with muscles. It has been well established that nerves will sprout vigorously if implanted onto a foreign muscle. If the muscle is already innervated by other motor neurons, the sprouting axons are unable to establish synaptic contact with the new target. On the other hand, if the host muscle is denervated, foreign nerves can now form new synapses and readily innervate the new target (Fex and Thesleff, 1967; Zalewski, 1970; Frank et al., 1975). We exploited this difference to determine if synaptic contact with muscle was necessary for the reappearance of the MO-1 epitope in motor neurons. The left hypoglossal nerve was transected and inserted into the ipsilateral sternomastoid muscle, which still retained its original innervation (Fig. 1D). Under these circumstances, virtually no MO-1 immunorcactivity was detected in the injured hypoglossal neurons, even after 6 weeks of contact with the sternomastoid muscle (Fig. 3, right column; Table 1). In contrast, if the sternomastoid muscle was denervated at the same time that the hypoglossal nerve was implanted (Fig. $1 E$ ), some of the injured hypoglossal neurons began to express MO-1 immunoreactivity 4 weeks after implantation, and the number of MO-1-positive cells increased with time (Fig. 3, middle column; Table 1). This slower, but significant, rate of recovery was more clearly seen when the percent of MO-1-positive cells was plotted against time following surgery, under each experimental paradigm (Fig. 4).

In order to quantify the rate of return of the MO-1 epitope following injury, the numbers of MO-1-positive neurons in each side of the hypoglossal nucleus were determined at different times after surgery (Table 1). In these studies, the entire hypoglossal nucleus was collected in $12 \mu \mathrm{m}$ thick serial sections; every other section was reacted with MO-1 and the immuno- reactive cells counted to determine the return of the epitope throughout the whole nucleus. The total number of immunopositive neurons on the experimental side was then compared with the number of stained neurons on the control side to determine the percent of cells that recover the MO- 1 epitope at each time point. This controlled for variation in $\mathrm{MO}-1$ staining intensity between sections. All three experimental procedures-nerve crush (Fig. $1 B$ ), nerve transection, and insertion into the innervated sternomastoid muscle (Fig. $1 D$ ), or insertion into the denervated sternomastoid muscle (Fig. 1E) - resulted in an essentially complete loss of immunoreactivity when examined at 1 week after surgery. Recovery was most rapid and complete following peripheral nerve crush, and by 4 weeks, the injured side of the nucleus had almost $80 \%$ of the numbers of immunoreactive neurons present on the uninjured control side. However, even under these favorable circumstances, recovery of MO-1positive cells did not return to $100 \%$, even after 6 weeks. Using Nissl staining of the intervening sections to determine cell survival, we found no difference in the total number of neurons on each side of the nucleus (data not shown). This comparison of extant cells and MO-1 reactive neurons indicated that approximately $20 \%$ of the injured neurons did not reacquire the MO- 1 epitope.

To ensure that the transected hypoglossal nerve remained in contact with the sternomastoid muscle throughout the experimental period, WGA was injected into this muscle a day before sacrifice. When sections of the hypoglossal nucleus were examined for the presence of the retrograde tracer, WGA-immunoreactivity was detectable in a few hypoglossal neurons by 2 weeks, and the numbers of labeled cells rose with time (Fig. 5). WGA-labeled neurons were observed both in animals where the hypoglossal nerve was implanted into a denervated (Fig. 5) as well as an innervated sternomastoid muscle (data not shown). Contact with muscle, thus, was sufficient for tracer uptake, even in the absence of synapse formation.

To investigate the efficacy of innervation by the implanted hypoglossal axons, neuromuscular junctions of the sternomastoid muscles were examined for the presence and distribution of pre- and postsynaptic elements. Sections of muscles were double labeled with $\alpha$-bungarotoxin, to locate postsynaptic sites, and with antibodies to synaptophysin, to visualize the presynaptic terminal. In control muscles, as well as muscles that were never denervated, synaptophysin-positive presynaptic terminals were present at all neuromuscular junctions identified by toxin binding (Fig. 6). Denervated muscles implanted with the hypoglossal nerves looked very different at early times after surgery. All postsynaptic sites were devoid of presynaptic synaptophysin immunoreactivity when examined at 1 and 2 weeks after denervation and implantation of the hypoglossal nerve. At 4 weeks, traces of synaptophysin immunoreactivity could be detected at some endplates, as identified by $\alpha$ - bungarotoxin binding (data not shown). Six weeks following surgery, staining of the presynaptic terminals appeared very robust, and was present at many endplates examined (Fig. 6). Thus, the timing of appearance of presynaptic specializations at postsynaptic sites coincided with the recovery of MO-1 immunoreactivity in hypoglossal neurons. In similar experiments, Zalewski (1970) found that no contractions or new endplates were observed if the hypoglossal nerve was implanted into an innervated sternomastoid muscle. These properties, characteristic of functional innervation, were only observed when the target muscle was first denervated. He further reported that the numbers of newly formed endplates, 

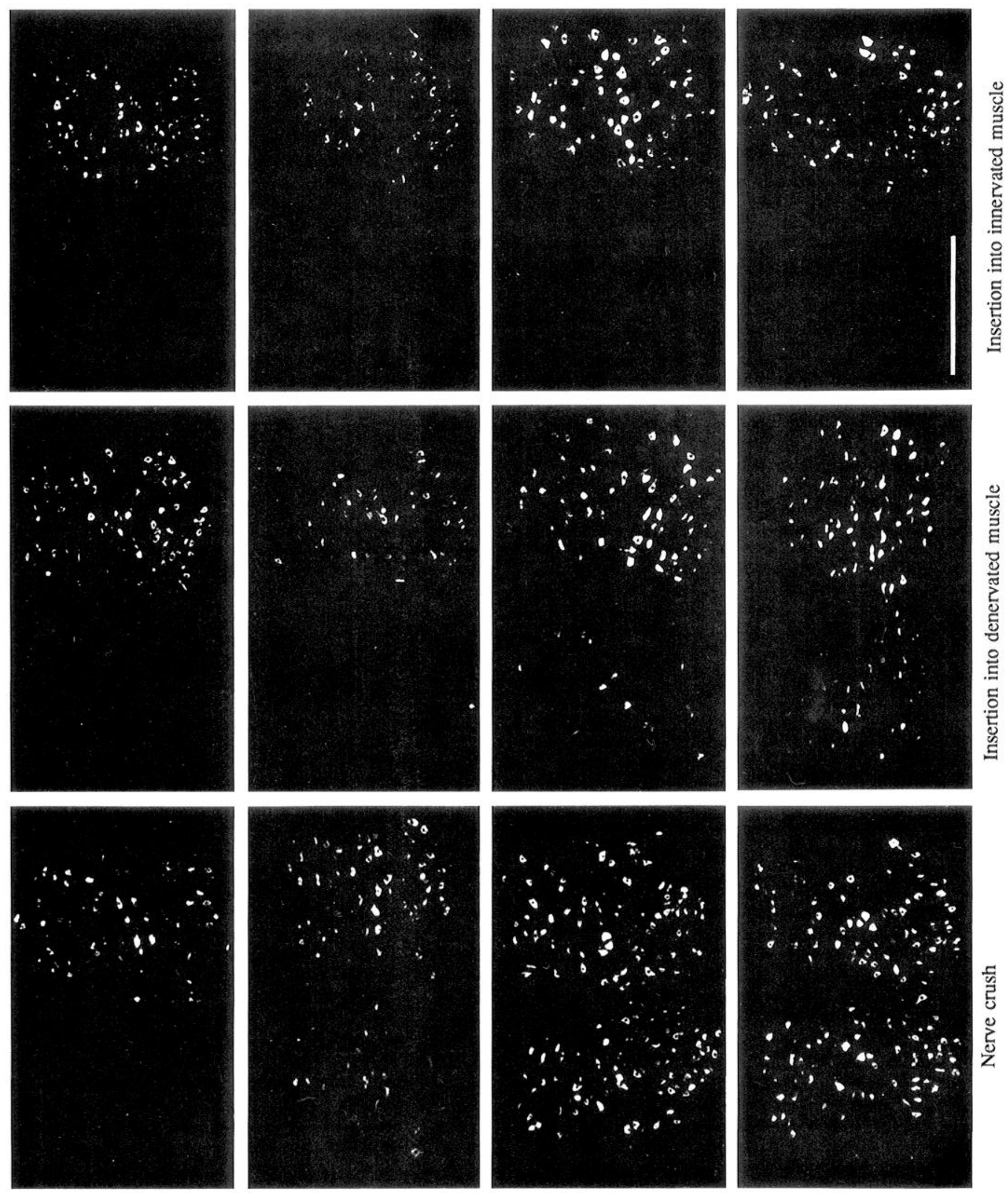

$$
\text { 一兽 }
$$

$N \frac{\frac{3}{8}}{3}$

$+\frac{2}{0}$

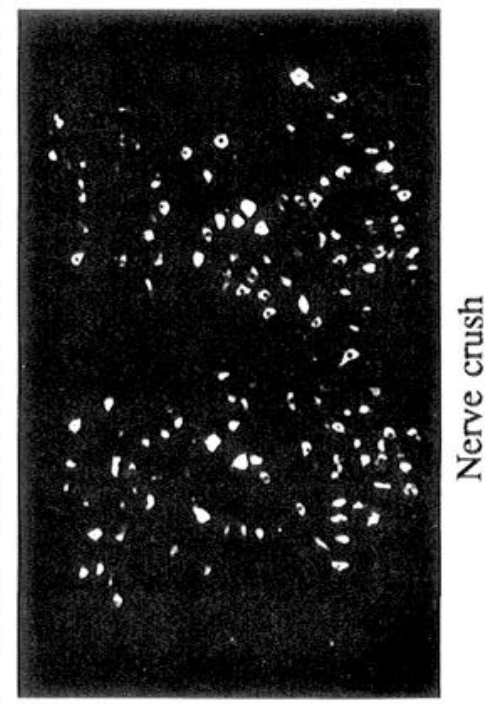

$0 \frac{3}{3}$ 


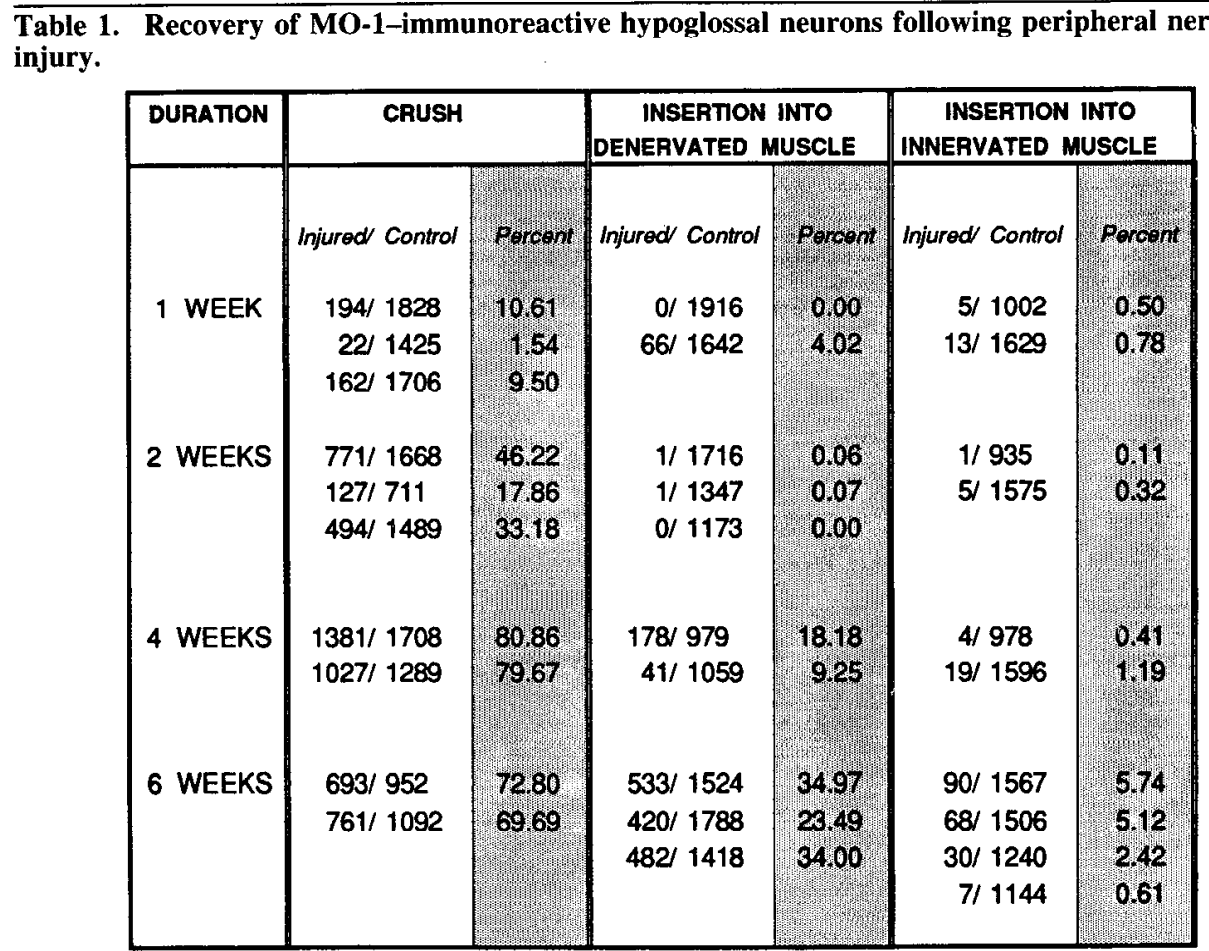

\begin{abstract}
In each animal, the number of MO-1-immunoreactive cells in the injured side was counted and divided by the number of MO-1-positive cells in the control contralateral side of the hypoglossal nucleus to obtain the percent recovery of the MO-1 epitope. This quantitative measure of motor neuronal recovery, examined at different times following injury, revealed that hypoglossal neurons recovered best, and most rapidly after nerve crush. However, the injured side did not show $100 \%$ recovery of MO-1-positive cells. (In sham-operated animals, the two halves of the nucleus had essentially equal numbers of immunoreactive cells.) When the hypoglossal nerve was inserted into a denervated muscle, $\mathrm{MO}-1$ hinding was not detectable until 4 weeks after injury, and then the numbers of immunoreactive cells increased with time. In contrast, virtually no hypoglossal neurons reacquired this epitope if the transected nerve was inserted into an innervated muscle.
\end{abstract}

first seen 1 month after implantation, increased greatly by 3 months. These findings support the notion that the recovery of MO-1 immunoreactivity in hypoglossal motor neurons coincided with functional innervation of the foreign target.

A parallel series of experiments was conducted to determine if the transmitter-synthesizing enzyme in motor neurons, ChAT, was also regulated by synaptic contact with muscles (Fig. 7). As with MO-1, transection of the hypoglossal nerve also resulted in the loss of ChAT-immunoreactivily. However, injured neurons that were placed in contact with either denervated or innervated muscles recovered near normal levels of the enzyme by 4-6 weeks. In fact, contact with muscle did not appear to be required for the return of ChAT; immunoreactivity for the enzyme was seen in animals where the hypoglossal nerve was chronically transected and ligated (data not shown; see also Borke et al., 1993).

\section{Discussion}

In adult animals, peripheral injury has dramatic morphological and biochemical consequences in motor neurons. A large num- ber of molecules are upregulated following axotomy (Maehlen et al., 1988; Olsson et al., 1989; Troy et al., 1990; Armstrong et al., 1991; Raivich et al., 1991; Borke et al., 1993; Yu, 1994). However, injured motor neurons lose two phenotypic markersthe transmitter synthesizing enzyme, choline acetyltransferase (ChAT), and the motor neuron-specific epitope that is recognized by monoclonal antibody MO-1. With time, immunoreactivity for ChAT returns; this recovery appears to be independent of reinnervation of muscles by the damaged motor ncurons (Fig. 7; Borke et al., 1993). In contrast, immunoreactivity with MO-1 remains undetectable in motor neurons prevented from reinnervating muscle fibers (Chiu et al., 1993). Thus, the expression of this motor neuronal property is controlled by a different regulatory mechanism.

The striking recovery of MO-1 immunoreactivity in motor neurons following nerve crush in both the spinal cord (Chiu et al., 1993) and the brainstem (Fig. 3) demonstrates that this motor neuron-specific epitope returns when contact is reestablished with the original muscle targets. These observations suggest that the MO-1 epitope may be regulated by (1) direct physical con$\leftarrow$

Figure 3. The return of MO-1 immunoreactivity to the left hypoglossal nucleus in experimental animals 1, 2, 4, and 6 weeks after surgery. In all panels, the left hypoglossal nucleus bore the injured neurons. MO-1 binding was not detected in the experimental side of the nucleus in all animals 1 week following the injury to the left hypoglossal nerve (top row). If the hypoglossal nerve was crushed (left column), the MO-1 epitope begins to return at 2 weeks, and by 4 weeks, practically all neurons had reacquired immunoreactivity for MO- 1 . In contrast, no MO-1 binding was observed in any animal where the transected hypoglossal nerve was inserted into an innervated foreign muscle (right column). If the foreign muscle was first denervated before implantation of the hypoglossal nerve, some MO-1 binding returned eventually to the injured motor neurons (middle column). Scale bar, $500 \mu \mathrm{m}$. 


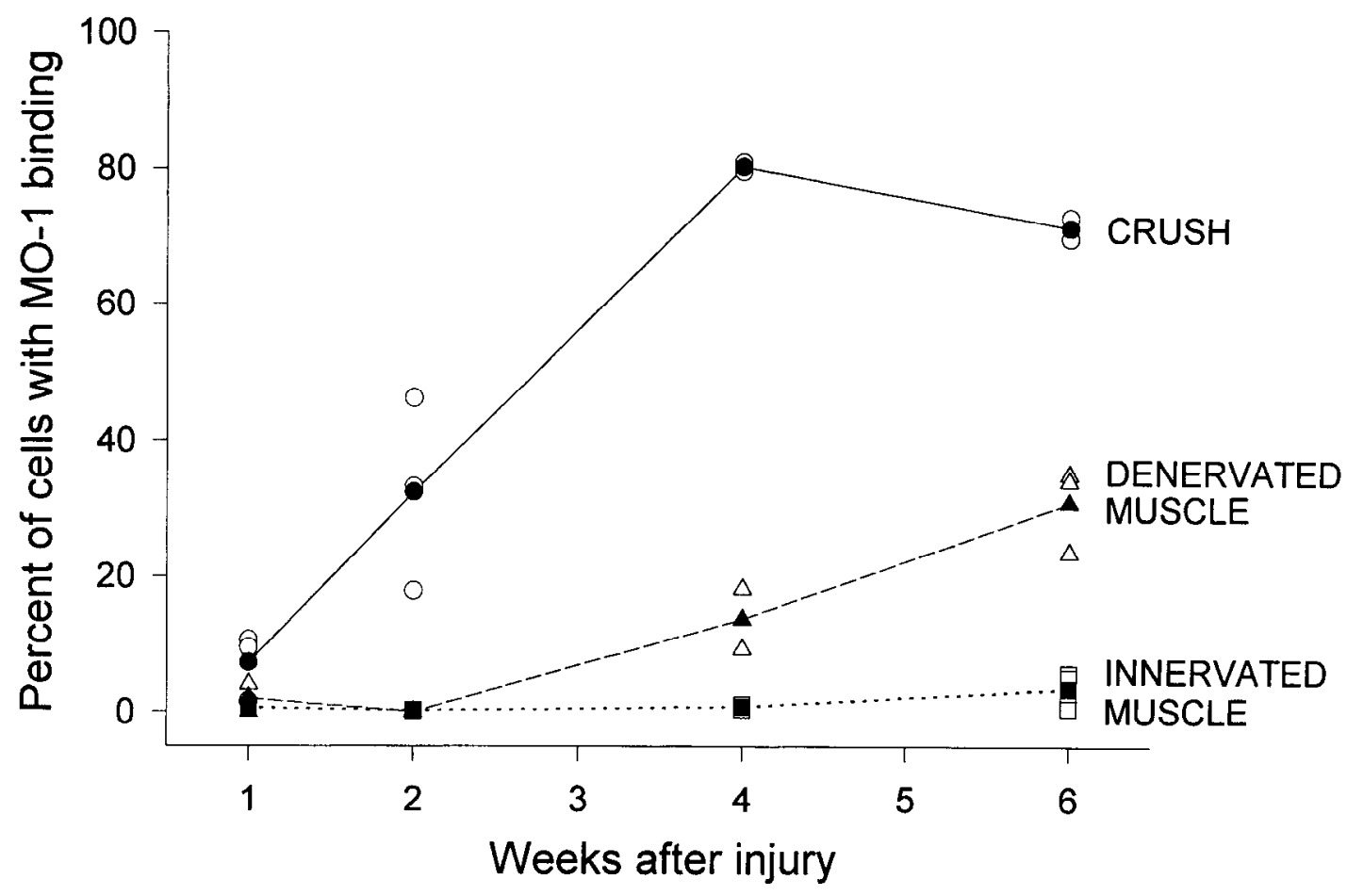

Figure 4. Recovery of MO-1 with time. The percentage of injured cells bearing MO-1 binding was plotted against time after injury to obtain the time course of recovery and reinnervation under each experimental paradigm. Return of MO-1 following insertion into the denervated sternomastoid (triangles) was slower than that seen after nerve crush (circles). However, no recovery was seen in neurons contacting innervated muscles (squares). Each open symbol represents data from one animal, and the closed symbols represent averages of MO-1-immunoreactive cells for each experimental condition.

tact with muscle fibers, and/or access to muscle-derived factors, (2) synaptic contact with muscles, or (3) a target-specific signal that matches motor neurons with their original postsynaptic muscle. The first possibility is unlikely because MO- 1 binding could not be detected in hypoglossal neurons that maintained longterm ( 6 weeks) contact with the innervated sternomastoid muscle (Fig. 3). In these experiments, the successful uptake and transport of WGA indicated that the axotomized neurons sprouted and remained attached to the foreign muscle for the duration of the experimental period. Similar retrograde studies were conducted by Vanden Noven et al. (1993), who concluded that axotomized motor neurons in adult rats remain viable, with no demonstrable impairment of their capacity for retrograde transport of macromolecules despite long-term deprivation of synaptic contact. We now find that contact with and access to soluble factors from the host muscle are not sufficient for these motor neurons to recover the MO-1 epitope.

In contrast, long-term contact with a denervated foreign muscle results in partial recovery of MO-1 immunoreactivity (Fig. 3). Physiological studies have documented that foreign motor nerves can form synapses with denervated, but not with innervated, muscle fibers (Fex and Thesleff, 1967; Zalewski, 1970; Frank et al., 1975). New presynaptic terminals can be established both at original synaptic sites and at ectopic locations on the denervated target (Zalewski, 1970; Weinberg et al,, 1981). Our results, thus, support the second possibility raised above, and indicate that motor neurons must be in synaptic contact with muscle fibers in order to acquire and maintain the MO- 1 epitope. However, reinnervation of the original target itself is not necessary for the recovery of MO-1 immunoreactivity, because MO- 1 binding is detected in neurons that have been induced to innervate a foreign muscle. Thus, synaptic contact with any skeletal muscle can support the return of this motor neuronal property.

The recovery of the MO-1 epitope following nerve crush is more rapid and extensive than following innervation of a forcign muscle (Fig. 4, Table 1). A number of factors may contribute to this difference. First, the return of the crushed axons to their original endplates is greatly facilitated by the mechanical and adhesive guidance provided by the extracellular matrix in the peripheral nerve. In contrast, transected axons that are inserted into the sternomastoid muscle have to navigate through a less charted and more challenging environment to synapse with their new target. Second, the sternomastoid muscle is much smaller than the tongue, providing fewer targets for synapse formation. In addition, muscles undergo atrophy when deprived of innervation for long periods of time; most of the denervated muscles appeared reduced in mass and density at the end of the experimental period. If the denervated sternomastoid muscle is unable to support as many motor neurons as the tongue, this may contribute to the lower rate of recovery of the MO-1 epitope.

It is interesting to note that even under optimal conditions for recovery, no more than $80 \%$ of the hypoglossal neurons reacquired MO-1 immunoreactivity. No obvious cell loss was found in the affected nucleus in brainstem sections reacted with Nissl stain. Since we do not know the number of synapses required to sustain MO-1 immunoreactivity in a motor neuron, it is unclear whether the $20 \%$ of injured neurons that remained unlabeled simply failed to synapse with a muscle fiber following nerve crush, or if their motor unit size was too small to induce detectable amounts of the MO-1 epitope. However, these results suggest that reinnervation, even under the most optimal circum- 


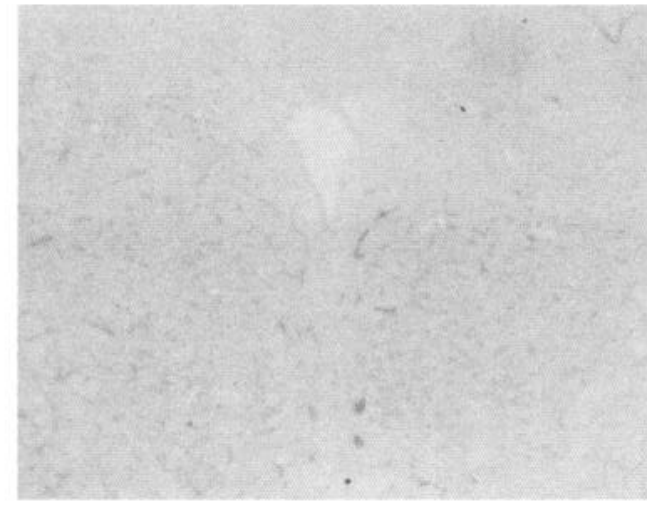

1 week

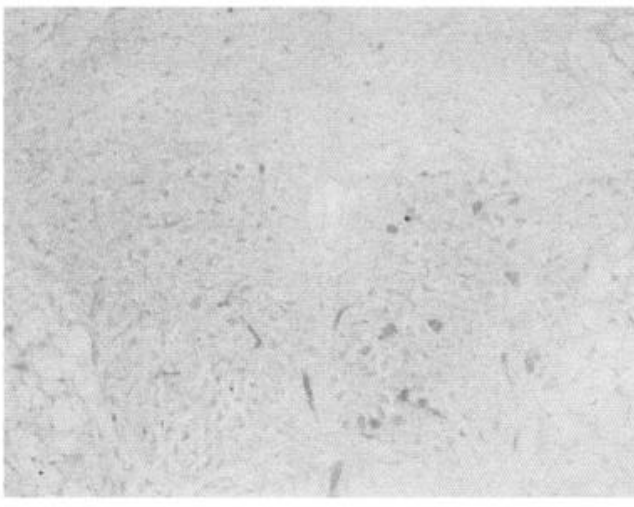

\section{2 weeks}

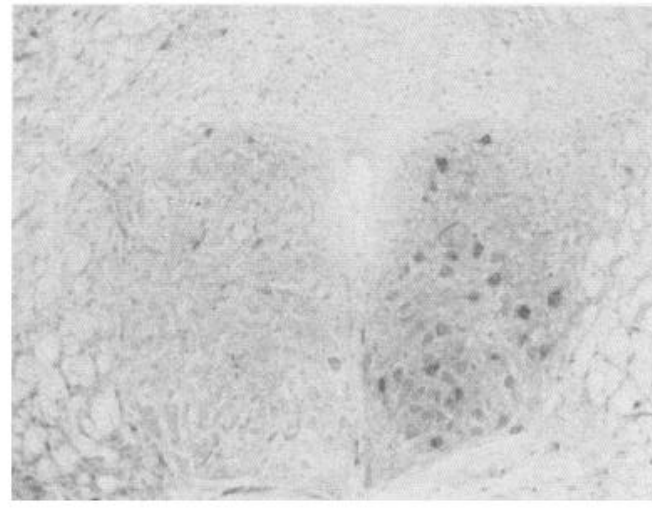

\section{4 weeks}

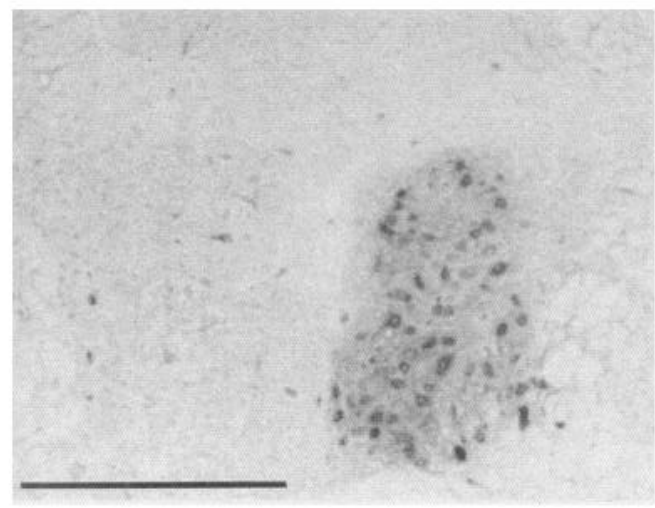

\section{6 weeks}

Figure 5. Retrograde labeling of hypoglossal neurons by injection of WGA into the sternomastoid muscle. The transected hypoglossal nerve was inserted into a denervated sternomastoid muscle, and WGA was injected into the target muscle a day before sacrifice. Increasing numbers of neurons in the injured side of the nucleus were labeled with time, indicating that these hypoglossal neurons sprouted and maintained contact with the sternomastoid muscle for the duration of the experiment. Scale bar, $500 \mu \mathrm{m}$.
Anti-synaptophysin
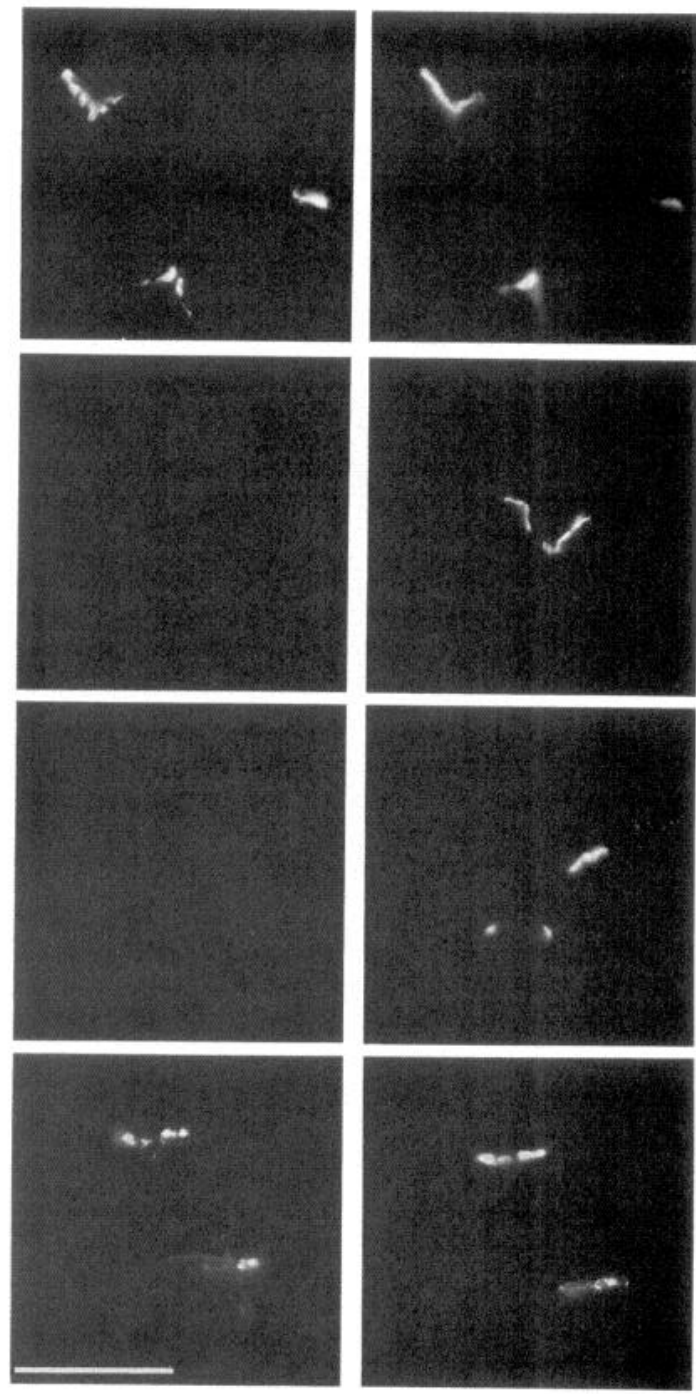

Figure 6. Pre- and postsynaptic elements at neuromuscular junctions in the skeletal muscle. Left and right panels show the same field viewed with different filters to reveal fluorescein-labeled, anti-synaptophysin (left), and rhodamine labeled $\alpha$-bungarotoxin (right). In normally innervated muscle, presynaptic nerve terminals, identified by antisynaptophysin, were apposed to postsynaptic sites, labeled with alpha-bungarotoxin. At 1 and 2 weeks after implanting the hypoglossal nerve into the denervated sternomastoid muscle, no presynaptic specializations were detected in the muscle. By 6 weeks, practically all endplates bore synaptophysin-stained nerve terminals. Scale bar, $100 \mu \mathrm{m}$.

stances, may not completely restore the original system of connectivity.

Denervated muscles produce a repertoire of factors and cell surface molecules distinct from that made by $\bar{n}$ nervated muscles (Chiu et al., 1986; Sanes et al., 1986; reviewed in McManaman and Oppenheim, 1993), and it is, thus, possible that access to these agents may contribute to the recovery of MO-1 binding in motor neurons. Recent experiments indicate that brain-derived neurotrophic factor (BDNF) prevents the loss of ChAT in axotomized motor neurons in vivo (Chiu et al., 1994), and is upregulated in denervated muscles (Koliatsos et al., 1993). Because axonal injury also upregulates Schwann cell production of BDNF as well as other neurotrophins (Heumann et al., 1987; 

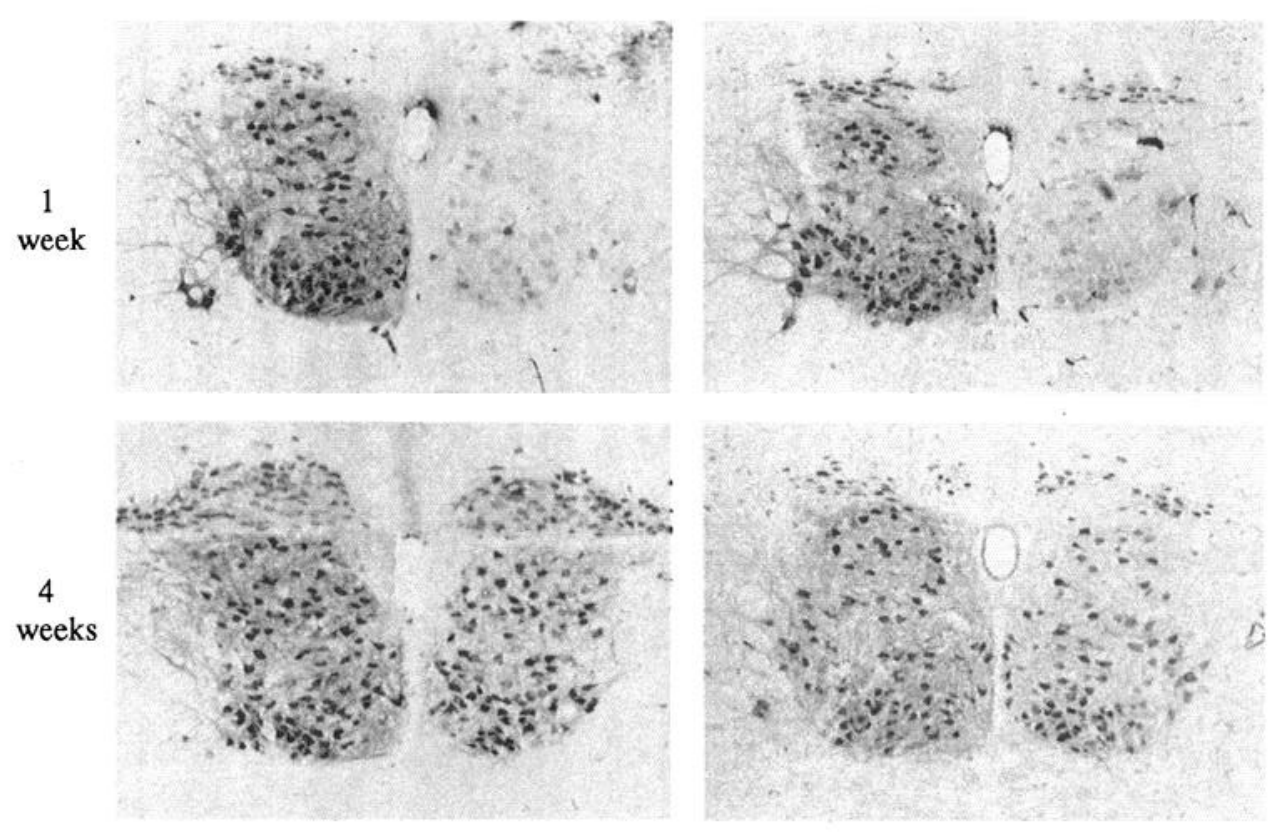

Figure 7. Synaptic contact with muscles is not required for the recovery of choline acetyltransferase immunoreactivity by axotomized motor neurons. In all panels, the injured hypoglossal neurons are located on the right side of the section. Choline acetyltransferase was lost from motor neurons within a week after transection of the ipsilateral hypoglossal nerve. However, immunoreactivity for the transmitter-synthesizing enzyme returned within 4-6 weeks to motor neurons in contact with either denervated or innervated muscles. Scale bar, $500 \mu \mathrm{m}$.

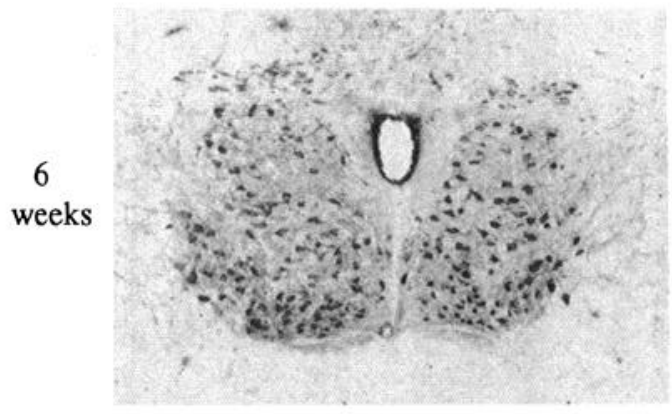

Insertion into denervated muscle

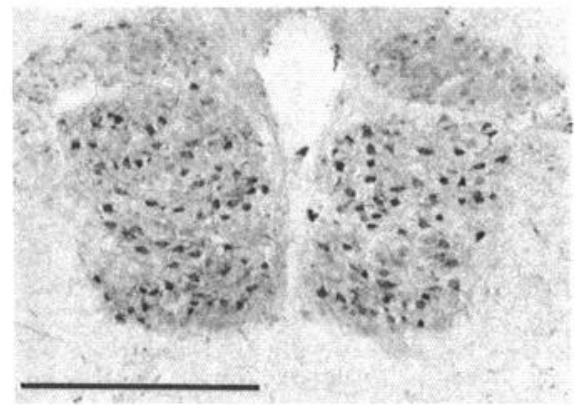

Insertion into innervated muscle
Meyer et al., 1992), it is likely that these agents promote the return of ChAT to axotomized motor neurons, even in the absence of reinnervation (Fig. 7; Borke et al., 1993). In contrast to ChAT, the MO-1 epitope does not return until motor neurons have successfully innervated a target, indicating that these two molecules are regulated by different mechanisms. Most importantly, in the unperturbed rodent nervous system, all MO-1-positive neurons are in contact with muscle fibers that are by definition, innervated, and therefore, not producing denervationinduced products. It is, thus, unlikely that molecules derived from denervated muscle are primarily responsible for the return of the MO-1 epitope.

In summary, a growing body of evidence points to the role of the innervated target in the regulation of the properties of the innervating cell. For example, changes initiated in the postsynaptic cell can alter the properties of the presynaptic terminal. Signals from muscle cells can modulate the presynaptic release of neurotransmitter at neuromuscular synapses developing in vitro (Harish and Poo, 1992). In vivo studies also reveal that loss of acetylcholine receptors at the postsynaptic membrane precedes nerve terminal withdrawal during synapse elimination (Balice-Gordon and Lichtman, 1993; Balice-Gordon et al., 1993). While these studies indicate that transynaptic interactions can have local consequences at the presynaptic terminal, our results, demonstrating that the maintenance of a motor neuronal epitope requires synaptic contact, provides direct evidence that retrograde signals from the muscle fiber regulates the biochemical phenotype of the presynaptic motor neuron.

\section{References}

Armstrong DM, Brady R, Hersh LB, Hayes RC, Wiley RG (1991) Expression of choline acetyltransferase and nerve growth factor receptor within hypoglossal motoneurons following nerve injury. J Comp Neurol 304:596-607.

Balice-Gordon RJ, Lichtman JW (1993) In vivo observations of pre-/ and postsynaptic changes during the transition from multiple to single innervation at developing neuromuscular junctions. J Neurosci 13: 834-855.

Balice-Gordon RJ, Chua CK, Nelson CC, Lichtman JW (1993) Gradual loss of synaptic cartels precedes axon withdrawal at developing neuromuscular junctions. Neuron 11:801-815.

Berg DK, Hall ZW (1975) Increased extrajunctional acetylcholine sensitivity produced by chronic post-synaptic blockade. J Physiol (Lond) 244:659-676.

Borke RC, Curtis M, Ginsberg C (1993) Choline acetyltransferase and calcitonin gene-related peptide immunoreactivity in motoneurons after different types of nerve injury. J Neurocytol 22:141-253.

Brenner HR, Herczeg A, Slater CR (1992) Synapse-specific expression of acetylcholine receptor genes and their products at original synaptic sites in rat soleus muscle fibers regenerating in the absence of innervation. Development 116:41-53.

Chen EW, Loera S, Chiu AY (1993) Monoclonal antibody MO-1 identifies motor neuron in synaptic contact with muscles. Soc Neurosci Abstr 19:642.

Chiu AY, Matthew WD, Patterson PH (1986) A monoclonal antibody that blocks the activity of a neurite regeneration promoting factor: 
studies on the binding site and its localization in vivo. J Cell Biol 103:1383-1398.

Chiu AY, Chen EW, Loera S (1993) A motor neuron-specific epitope and the low affinity nerve growth factor receptor display reciprocal pattern of expression during development, axotomy, and regeneration. J Comp Neurol 328:351-363.

Chiu AY, Chen EW, Loera S (1994) Distinct neurotrophic responses of axotomized motor neurons to BDNF and CNTF in adult rats. Neuroreport 5:693-696.

Conner EA. Smith MA (1994) Retrograde signaling in the formation and maintenance of the neuromuscular junction. J Neurobiol 25:722739.

Eftimie R, Brenner HR, Buonanno A (1991) Myogenin and MyoD join a family of skeletal muscle genes regulated by electrical activity. Proc Natl Acad Sci USA 88:1349-1353.

Erzurumlu RS, Jhaveri S, Takahashi H, McKay RDG (1993) Targetderived influences on axon growth modes in cultures of trigeminal neurons. Proc Natl Acad Sci USA 90:7235-7239.

Falls DL, Harris DA, Johnson FA, Morgan MM, Corfas G, Fischbach GD (1990) Mr 42,000 ARIA: a protein that may regulate the accumulation of acetylcholine receptors at developing chick neuromuscular junctions. Cold Spring Harbor Symp Quant Biol 15:397-406.

Fambrough DM (1979) Control of acetylcholine receptors in skeletal muscle. Physiol Rev 59:165-227

Fex S, Thesleff S (1967) The time required for innervation of denervated muscles by nerve implants. Life Sci 6:635-639.

Fontaine B, Klarsfeld A, Changeux JP (1987) Calcitonin genc-related peptide and muscle activity regulate acetylcholine receptor a-subunit mRNA levels by distinct intracellular pathways. J Cell Biol 105: 1337-1342.

Frank E, Jansen JKS, Lomo T, Westgaard RH (1975) The interaction between foreign and original motor neurones innervating the soleus muscle of rats. J Physiol (Lond) 247:725-743.

Goldman D, Brenner HR, Heinemann S (1988) Acetylcholine receptor $\alpha-, \beta-, \gamma-$, and $\delta-/$ subunit mRNA levels are regulated by muscle activity. Neuron 7:649-658.

Goldman D, Carlson B, Staple J (1991) Induction of adult-type nicotinic acetylcholine gene expression in noninnervated regenerating muscle. Neuron 7:649-658.

Gu Y, Hall ZW (1988) Immunological evidence for a change in subunits of the acetylcholine receptor in developing and denervated rat muscle. Neuron 1:117-125.

Gunning P, Hardeman E (1991) Multiple mechanisms regulate muscle fiber diversity. FASEB J 5:3064-3070.

Hall ZW, Sanes JR (1993) Synaptic structure and development: the neuromuscular junction. Cell/Neuron [Suppl] 72/10:99-121.

Harish OE, Poo M-m (1992) Retrograde modulation at developing neuromuscular synapses: involvement of $\mathrm{G}$ protein and arachidonic acid cascade. Neuron 9:1201-1209.

Hawkins RD, Zhuo M, Arancio O (1994) Nitric oxide and carbon monoxide as possible retrograde messengers in hippocampal long term potentiation. J Neurobiol 25:652-665.

Haydon PG, Zoran MJ (1994) Retrograde regulation of presynaptic development during synaptogenesis. J Neurobiol 25:694-706.

Heumann R, Korsching S, Bandtlow C, Thoenen H (1987) Changes of nerve growth factor synthesis in non-neuronal cells in response to sciatic nerve transection. J Cell Biol 104:1623-1631.

Jansen JKS, Fladby T (1990) The perinatal reorganization of the innervation of skeletal muscle in mammals. Prog Neurobiol 34:39-90.

Jessell TM, Kandel ER (1993) Synaptic transmission: a bidirectional and self-modifiable form of cell-cell communication. Cell/Neuron (Suppl) 72/10:1-30.

Jo AA, Burden SJ (1992) Synaptic basal lamina contains a signal for synapse-specific transcription. Development 115:673-680.

Klarsfeld A, Laufer R, Fontaine B, Devillers-Thiery A, Dubreuil C, Changeux JP (1989) Regulation of the muscle AChR a subunit gene expression by electrical activity: involvement of protein kinase $\mathrm{C}$ and $\mathrm{Ca}^{2+}$. Neuron 2;1229-1236.

Koliatsos VE, Clatterbuck RE, Winslow JW, Cayouette MH, Price DL (1993) Evidence that brain-derived neurotrophic factor is a trophic factor for motor neurons in vivo. Neuron 10:359-367.

Korsching S (1993) The neurotrophic factor concept: a reexamination. J Neurosci 13:2739-2748.

Kuno M (1990) Target dependence of motoneuronal survival: the current status. Neurosci Res 9:155-172.
Leber SM, Breedlove SM, Sanes JR (1990) Lineage, arrangement and death of clonally related neurons in chick spinal cord. J Neurosci 10 : 2451-2462.

Maehlen J, Daa Schroder H, Klareskog L, Olsson T, Kristensson K (1988) Axutony induces MHC class I antigen expression on rat nerve cells. Neurosci Lett 92:8-13.

McMahan UJ, Horton SE, Werle MJ, Honig LS, Kroger S, Ruegg MA, Escher G (1992) Agrin isoforms and their role in synaptogenesis. Curr Opin Cell Biol 4:869-874.

McManaman JL, Oppenheim RW (1993) Skeletal muscle-derived neurotrophic factors and motoneuron development. In: Neurotrophic factors (Loughlin SE, Fallon JH, eds), pp 475-487. New York: Academic.

Meyer M, Matsuoka I, Wetmore C, Olson L, Thoenen H (1992) Enhanced synthesis of brain-derived neurotrophic factor in the lesioned peripheral nerve: different mechanisms are responsible for the regulation of BDNF and NGF mRNA. J Cell Biol 119:45-54.

Murphey RK, Davis GW (1994) Retrograde signaling at the synapse. J Neurobiol 25:595-598.

New HV, Mudge AW (1986) Calcitonin gene-related peptide regulates muscle acetylcholine receptor synthesis. Nature 323:809-811.

Nishi R (1994) Target-derived molecules that influence the development of neurons in the avian ciliary ganglion. J Neurobiol 25:612619

Olsson T, Kristensson K, Ljungdahl A, Maehlen J, Holmdahl R, Klareskog L (1989) Gamma-interferon-like immunoreactivity in axotomized rat motor neurons. J Neurosci 9:3870-3875.

Patterson PH, Nawa H (1993) Neuronal differentiation factors/cytokines and synaptic plasticity. Cell/Neuron [Suppl] 72/10: 123-137.

Phelps PE, Barber RP, Vaughn JE (1988) Generation patterns of four groups of cholinergic neurons in rat cervical spinal cord: a combined tritiated thymidine autoradiographic and choline acetyltransferase immunocytochemical study. J Comp Neurol 273:459-472.

Phelps PE. Barber RP, Vaughn JE (1991) Embryonic development of choline acetyltransferase in thoracic spinal motor neurons. Somatic and autonomic neurons may be derived from a common cellular group. J Comp Neurol 307:1-10.

Raivich G, Gehrmann J, Kreutzberg GW (1991) Increase of macrophage colony-stimulatory factor and granulocyte-macrophage colonystimulating factor receptors in the regenerating rat facial nucleus. $\mathbf{J}$ Neurosci Res 30:682-686.

Rubenstein NA, Mabuchi K, Pepe F, Salmons S, Gergely J, Sreter FA (1978) Use of type-specific anti-myosins to demonstrate the transformation of individual fibers in chronically stimulated rabbit fast muscles. J Cell Biol 179:252-261.

Salmons S, Sreter FA (1976) Significant of impulse activity in the transformation of skeletal muscle type. Nature 263:30-34.

Sanes JR, Chiu AY (1983) The basal lamina of the neuromuscular junction. Cold Spring Harb Symp Quant Biol 48:667-678.

Sanes JR, Schachner M, Covault J (1986) Expression of several adhesive macromolecules (N-CAM, L1, J1, NILE, uvomorulin, laminin, fibronectin, and a heparan sulfate proteoglycan) in embryonic, adult, and denervated adult skeletal muscle. J Cell Biol 102:420-431.

Schotzinger R, Yin X, Landis S (1994) Target determination of neurotransmitter phenotype in sympathetic neurons. J Neurobiol 25:620639.

Schuman EM, Madison DV (1994) Nitric oxide and synaptic function. Annu Rev Neurosci 147:153-183.

Troy CM, Muma NA, Greene LA, Price DL, Shelanski ML (1990) Regulation of peripherin and neurofilament expression in regenerating rat motor neurons. Brain Res 529:232-238.

Urakami H, Chiu AY (1990) $\Lambda$ monoclonal antibody that recognizes somatic motor neurons in the adult rat nervous system. J Neurosci 10:620-630.

Vanden Noven SV, Wallace N, Muccio D, Turtz A, Pinter MJ (1993) Adult spinal motor neurons remain viable despite prolonged absence of functional synaptic contact with muscle. Exp Neurol 123:147-156.

Voyvodic JT (1989) Target size regulates calibre and myelination of sympathetic axons. Nature 342:430-432.

Weinberg CB, Sanes JR, Hall ZW (1981) Formation of neuromuscular junctions in adult rats: accumulation of acetylcholine receptors, acetylcholinesterase and components of synaptic basal lamina. Dev Biol 84:255-266.

Wood SJ, Pritchard J, Sofroniew MV (1990) Re-expression of nerve 
growth factor receptor after axonal injury recapitulates a developmental event in motor neurons: differential regulation when regeneration is allowed or prevented. Eur J Neurosci 2:650-657.

Yu WHA (1994) Nitric oxide synthase in motor neurons after axotomy. J Histochem Cytochem 42:451-457.
Zalewski AA (1970) Effects of reinnervation on denervated skeletal muscle by axons of motor, sensory, and sympathetic neurons. Am J Physiol 219:1675-1679. 